\title{
Galactomannans from the cell walls of species of Paecilomyces sect. Paecilomyces and their teleomorphs as immunotaxonomic markers
}

\author{
Jezabel Domenech, ${ }^{1}$ Alicia Prieto, ${ }^{1}$ Isabel Barasoaín, ${ }^{1}$ \\ Begoña Gómez-Miranda, ${ }^{1}$ Manuel Bernabé ${ }^{2}$ and J. Antonio Leal'
}

Author for correspondence: J. Antonio Leal. Tel: +34 9156118 00. Fax: +34 915627518. e-mail: aleal@cib.csic.es

1 Centro de Investigaciones Biológicas, c/Velázquez 144.28006-Madrid, Spain

2 Instituto de Química Orgánica, Grupo de Carbohidratos, c/Juan de la Cierva 3.28006-Madrid, Spain

\begin{abstract}
An alkali-extractable and water-soluble fraction (F1S) was obtained from cell walls of Paecilomyces variotii and species of the related genera Talaromyces, Byssochlamys and Thermoascus. The structure of the main polysaccharide of these fractions was studied and found to consist of a core of $(1 \rightarrow 6)-\alpha-$ mannopyranose partially substituted at $0-2$ by chains of galactofuranose and shorter chains of mannopyranose. The differences in the regularity of the branching points and the length of the galactofuranose side chains are useful to distinguish between species. These differences were detected by immunological methods, since highly specific polyclonal antibodies were raised against these polysaccharides. Mycelium of $P$. variotii CBS $990.73 \mathrm{~A}$ was stained by indirect immunofluorescence. The polysaccharides studied in this work differ from the one described for species from section Isarioidea, and this is another indication of the heterogeneity of the genus Paecilomyces.
\end{abstract}

Keywords: Paecilomyces, cell wall, galactomannan, chemotaxonomy, fungal antibodies

\section{INTRODUCTION}

Paecilomyces is a genus of filamentous fungi closely related to Penicillium (Brown \& Smith, 1957). Taxonomically, the genus is subdivided into two sections. Section Paecilomyces contains mesophilic, thermotolerant and thermophilic species and colonies with yellow-brown to brownish colours, with perfect states in Talaromyces, Byssochlamys and Thermoascus. Section Isarioidea contains mesophilic species with purple-, pink-, green- or yellow-coloured colonies. The type species of section Paecilomyces is P. variotii. The history of Paecilomyces, its delimitation and its relationships to another genera have been reviewed by Samson (1974).

These genera are economically important since some species are responsible for food contamination and spoilage (King et al., 1969; Engel \& Teuber, 1991), can infect immunodeficient humans (Byrd et al., 1992) or are pathogenic for invertebrate animals such as the silk-worm (Bombyx mori) (Aoki \& Yanase, 1970).

Taxonomy based only on the morphology of these genera is sometimes unclear. The use of biochemical and molecular techniques is needed in order to give some insight into the classification of related groups of fungi (Taylor et al., 1990; Berbee et al., 1995). The fungal cell wall is mainly composed of polysaccharides, which have proved to be useful chemotaxonomic and antigenic markers for identification purposes (Bartnicki-García, 1970; Weijman et al., 1982; Weijman \& Golubev, 1987; Weijman \& Van der Walt, 1989; Kamphuis et al., 1992; Leal, 1994; Leal \& Bernabé, 1998).

The finding that fungal polysaccharides have immunological properties, and that some of them are almost genus-specific (Notermans \& Soentoro, 1986), enhanced interest in the elucidation of the structure of these molecules since they might be used as chemotaxonomic characters. Most studies on serological properties of fungal polysaccharides deal with exopolysaccharides (Notermans \& Soentoro, 1986; Notermans et al., 1987; De Ruiter et al., 1992) and cell wall glycoproteins (Gailliez \& Poulain, 1988; Sridhara et al., 1990; Hearn, 1991). An antigenic water-soluble galactomannan isolated from cell walls of Paecilomyces fumosoroseus and Paecilomyces farinosus (section Isarioidea) has been studied in our laboratory (Domenech et al., 1996). In the present research we report on the structural and immunological characterization of polysaccharides purified from cell walls of species of section Paecilomyces and discuss their use as chemotaxonomic characters for the delimitation of the section. 


\section{METHODS}

Micro-organisms and culture media. Fungal isolates used were: P. variotii CBS 990.73A, CBS 323.34, CBS 339.51 and CBS 371.70; Talaromyces leycettanus (teleomorph of Paecilomyces leycettanus) CBS 275.70; Talaromyces byssochlamydoides (teleomorph of Paecilomyces byssochlamydoides)CBS 533.71; Byssochlamys fulva (teleomorph of Paecilomyces fulvus) CBS 604.71; Byssochlamys nivea (teleomorph of Paecilomyces niveus) CBS 100.11; and Thermoascus crustaceus (teleomorph of Paecilomyces crustaceus) CBS 114.66. The isolates were maintained on slants of Bacto potatodextrose agar supplemented with $1 \mathrm{~g}$ yeast extract (Difco) $\mathrm{l}^{-1}$. The culture medium and growth conditions were as previously described (Gómez-Miranda et al., 1990).

Wall material preparation and fractionation. Wall material was obtained as reported by Gómez-Miranda et al. (1990). Cell wall material $(8 \mathrm{~g})$ was repeatedly extracted with $1 \mathrm{M}$ $\mathrm{NaOH}(300 \mathrm{ml})$ at $20^{\circ} \mathrm{C}$. After centrifugation, the supernatants were combined and an equal volume of $96 \%$ ethanol was added. The precipitate was collected by centrifugation, dialysed against running tap water and then freeze-dried. This polysaccharidic material $(500 \mathrm{mg})$ was suspended in distilled water $(100 \mathrm{ml})$, stirred at room temperature for $2 \mathrm{~h}$ and centrifuged. The precipitate was extracted again as described above and the supernatant solutions were combined and freeze-dried (F1S).

Isolation of polysaccharides from F1S. Fraction F1S (190 mg) was dissolved in $3 \mathrm{ml}$ distilled water and centrifuged at $13000 \mathrm{~g}$ for $15 \mathrm{~min}$ to eliminate insoluble material. The supernatant was added to a column $(90 \times 3 \mathrm{~cm})$ of Sepharose CL-6B and eluted with distilled water (flow rate $21.4 \mathrm{ml} \mathrm{h}^{-1}$ ). Fractions of $2.5 \mathrm{ml}$ were collected and monitored for carbohydrate by the phenol-sulphuric acid method (Dubois et al., 1956). Appropriate fractions were combined, concentrated to a small volume $(15 \mathrm{ml})$ and freeze-dried.

Isolation of the mannan core. A sample of each polysaccharide $\left(100 \mathrm{mg}\right.$ ) was treated with $20 \mathrm{ml} 0.05 \mathrm{M} \mathrm{H}_{2} \mathrm{SO}_{4}$ at $100{ }^{\circ} \mathrm{C}$ for $6 \mathrm{~h}$. The degraded polysaccharide was dialysed against distilled water (exclusion limit $3000 \mathrm{Da}$ ), concentrated to a small volume $(10 \mathrm{ml})$ and freeze-dried.

Chemical analyses. Monosaccharides were released by Saeman hydrolysis (Adams, 1965) and analysed by GLC as their corresponding alditol acetates as previously described (Gómez-Miranda et al., 1981). Methylation analysis and GLCMS of the derivatives were performed as described by Domenech et al. (1996). Permethylated samples were subjected to reductive cleavage as described by Gray (1987) in order to identify the ring size (pyranose or furanose) of the sugar residues. The partially methylated anhydroalditol acetates obtained were analysed by GLC-MS using a fused silica SPB1 column and a temperature range of 150 to $200{ }^{\circ} \mathrm{C}(3 \mathrm{~min}$ initial hold and ramp rate $3{ }^{\circ} \mathrm{C} \mathrm{min}^{-1}$ ). Absolute configuration was determined according to Gerwig et al. (1978) by GLC-MS of the tetra-O-TMSi- $(+)$-2-butylglycosides obtained. Protein was determined by the Lowry method.

NMR spectroscopy. The polysaccharides (approx. $20 \mathrm{mg}$ ) obtained after column chromatography were dissolved in $\mathrm{D}_{2} \mathrm{O}$ $(1 \mathrm{ml})$ followed by centrifugation $(10000 \mathrm{~g}$ for $20 \mathrm{~min})$ and lyophilization of the supernatant. The process was repeated twice and the final sample was dissolved in $\mathrm{D}_{2} \mathrm{O}(0.7 \mathrm{ml}$, $99 \cdot 98 \%$ D). ${ }^{1} \mathrm{H}$ - and ${ }^{13} \mathrm{C}-\mathrm{NMR}$ spectra were recorded at $40{ }^{\circ} \mathrm{C}$ on a Varian INOVA 300 spectrometer. Proton chemical shifts refer to residual HDO at $\delta 4 \cdot 61$ p.p.m. Carbon chemical shifts refer to internal acetone at $\delta 31.07$ p.p.m.
Antibody production and serology. Antibodies were obtained by immunization of rabbits with F1S-B polysaccharide (the major fraction isolated by gel permeation chromatography of F1S on Sepharose CL-6B) of P. variotii CBS 990.73A, P. fumosoroseus CBS 375.70 and Eupenicillium crustaceum CBS 635.70. The protocols for immunization and titration by ELISA were as previously described (Domenech et al., 1996) except that the ELISA plates were coated with different concentrations of polysaccharide $\left(40-400 \mathrm{~g} \mathrm{ml}^{-1}\right)$ depending on the antigens. The specificity of the antisera obtained was tested by inhibition studies (Domenech et al., 1996). The polysaccharides isolated from all species tested in this work and the water-soluble polysaccharide from E. crustaceum (Leal et al., 1993) were used as inhibitors. Staining of $P$. variotii CBS 990.73A was carried out by immunofluorescence under the same conditions as reported by Domenech et al. (1996), but in this case it was not necessary to adsorb the secondary antibody with mycelium since nonspecific staining was not observed.

\section{RESULTS}

\section{Purification and chemical composition of the polysaccharides}

In all species, two polysaccharides were isolated from the alkali- and water-soluble material (F1S, 3-6\% of dry cell walls) by gel permeation through Sepharose CL6B. A small unretained fraction (F1S-A, 3·3-10\%), mainly composed of glucose, was not further analysed. The major polysaccharide (F1S-B, 70-80\%) was rechromatographed and eluted as a single peak. Monosaccharide analysis of the purified polysaccharides gave D-mannose $(23-45 \%)$, D-galactose $(16-43 \%)$, and D-glucose (3-9\%). No protein was detected.

Table 1. Methylation analysis of F1S-B polysaccharides from Paecilomyces species

THC, Th. crustaceus CBS 144.66; PVA, P. variotii CBS 990.73A; BFU, B. fulva CBS 604.71; BNI, B. nivea CBS 100.11; TBY, Ta. byssochlamydoides CBS 533.71; TLE, Ta. leycettanus CBS 275.70; -, none detected. All values are means of at least three determinations.

\begin{tabular}{|c|c|c|c|c|c|c|}
\hline \multirow[t]{2}{*}{ Linkage type } & \multicolumn{6}{|c|}{ Relative percentage } \\
\hline & THC & PVA & BFU & $\mathrm{BNI}$ & TBY & TLE \\
\hline Glcp- $(1 \rightarrow$ & - & $2 \cdot 2$ & $1 \cdot 6$ & - & - & $1 \cdot 9$ \\
\hline Galf- $(1 \rightarrow$ & $11 \cdot 2$ & $6 \cdot 3$ & $9 \cdot 2$ & $5 \cdot 9$ & $6 \cdot 6$ & $6 \cdot 3$ \\
\hline$\rightarrow 5)$-Galf-(1 $\rightarrow^{*}$ & $30 \cdot 5$ & $34 \cdot 0$ & $27 \cdot 5$ & $15 \cdot 8$ & $44 \cdot 2$ & $16 \cdot 5$ \\
\hline$\rightarrow 6)$-Galf-(1 $\rightarrow$ & $3 \cdot 4$ & $4 \cdot 0$ & $3 \cdot 5$ & $2 \cdot 5$ & - & - \\
\hline $\operatorname{Man} p-(1 \rightarrow$ & $4 \cdot 3$ & $2 \cdot 2$ & $4 \cdot 0$ & $3 \cdot 7$ & $9 \cdot 0$ & $16 \cdot 0$ \\
\hline$\rightarrow 2)-\operatorname{Man} p-(1 \rightarrow$ & $7 \cdot 4$ & $7 \cdot 0$ & $10 \cdot 9$ & $11 \cdot 4$ & $8 \cdot 7$ & $12 \cdot 5$ \\
\hline$\rightarrow 6)-\operatorname{Man} p-(1 \rightarrow$ & $30 \cdot 1$ & $32 \cdot 5$ & $33 \cdot 6$ & $44 \cdot 0$ & $20 \cdot 2$ & $21 \cdot 2$ \\
\hline$\rightarrow 2,6)-\operatorname{Man} p-(1 \rightarrow$ & $10 \cdot 5$ & $11 \cdot 6$ & $9 \cdot 5$ & $14 \cdot 1$ & $11 \cdot 8$ & $26 \cdot 0$ \\
\hline
\end{tabular}

* The identity of $\rightarrow 5)$-Gal $f-(1 \rightarrow$ was determined by reductive cleavage. 
(a)

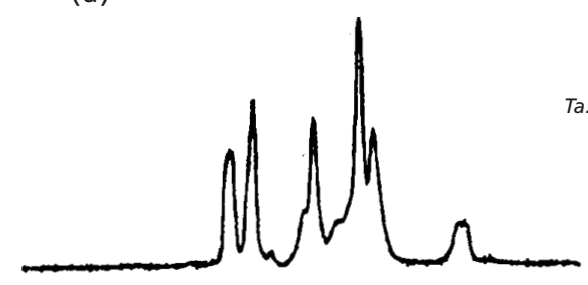

(b)

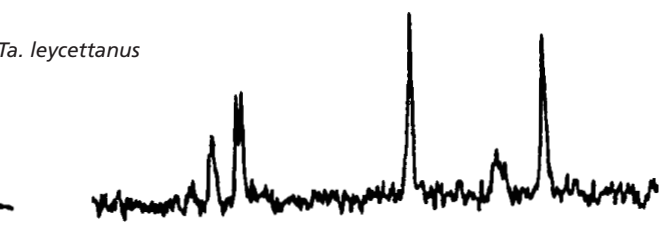

B. nivea

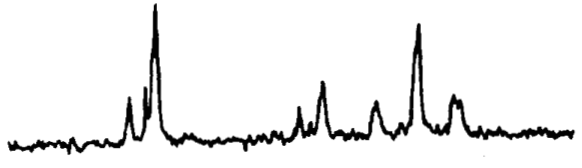

Ta. byssochlamydoides

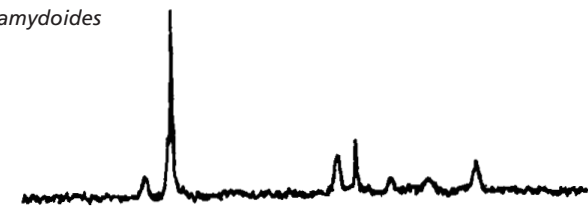

Th. crustaceus
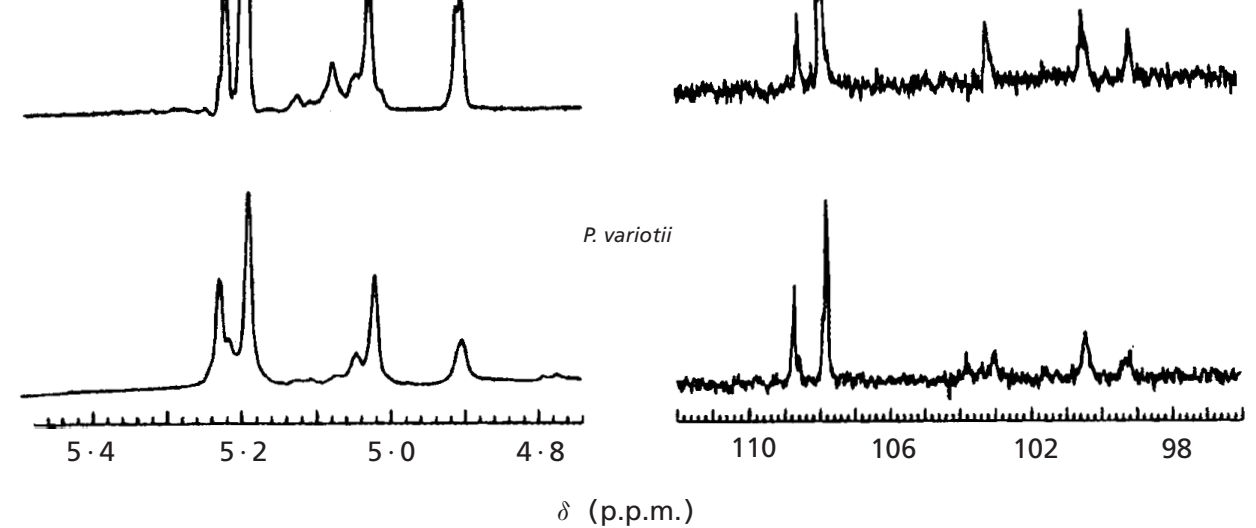

Fig. 1. ${ }^{1} \mathrm{H}$ - (a) and ${ }^{13} \mathrm{C}$ - (b) NMR spectra of the anomeric region of fractions F1S-B from the fungal species studied. The spectrum of fraction F1S-B from $B$. fulva (not shown) was similar to that depicted for $P$. variotii.

\section{Structural studies of the polysaccharides}

The water-soluble polysaccharides F1S-B were studied using a combination of chemical and spectroanalytical techniques. The methylation results (Table 1) demonstrated that all the polysaccharides contained almost identical substituted galactofuranose and mannopyranose residues, although in different proportions. Three of them had also very small amounts $(2 \%)$ of terminal glucopyranose. All the ${ }^{1} \mathrm{H}-\mathrm{NMR}$ spectra (Fig. 1a) showed broad uneven signals coexisting with small signals, indicative of irregular polysaccharides. In addition, the ${ }^{13} \mathrm{C}$-NMR spectra (Fig. 1b) contained sharp and broad signals, suggesting the presence of a low mobility backbone with side chains of higher flexibility (Rath et al., 1995; Prieto et al., 1997). The chemical shifts of the sharp signals had values over 105 p.p.m., indicative of $\beta$-galactofuranose units, while the broad signals were assigned to the mannopyranose residues. These values are in agreement with the existence of $\beta$ galactofuranose chains linked to a mannan core (Prieto et al., 1997). Some of the polysaccharides were analysed by comparison with known polysaccharides. The signals for the galactofuranose residues of $P$. variotii and $B$. fulva were found to be closely related to those of Penicillium expansum (Parra et al., 1994) since (1 $\rightarrow 5$ )- 
Table 2. Methylation analysis of the mannan core obtained from F1S-B of Paecilomyces species

THC, Th. crustaceus CBS 144.66; PVA, P. variotii CBS 990.73A; BNI, B. nivea CBS 100.11; TBY, Ta.

byssochlamydoides CBS 533.71; TLE, Ta. leycettanus CBS 275.70. All values are means of at least three determinations.

\begin{tabular}{|llllll|}
\hline Linkage type & \multicolumn{5}{c|}{ Relative percentage } \\
\cline { 2 - 6 } & THC & PVA & BNI & TBY & TLE \\
\hline Manp- $(1 \rightarrow$ & $21 \cdot 4$ & $20 \cdot 6$ & $19 \cdot 1$ & $28 \cdot 1$ & $27 \cdot 7$ \\
$\rightarrow$ 2)-Manp-(1 $\rightarrow$ & $16 \cdot 3$ & $17 \cdot 1$ & $16 \cdot 2$ & $17 \cdot 0$ & $15 \cdot 8$ \\
$\rightarrow$ 6)-Manp-(1 $\rightarrow$ & $50 \cdot 1$ & $48 \cdot 2$ & $50 \cdot 2$ & $24 \cdot 6$ & $26 \cdot 7$ \\
$\rightarrow$ 2,6)-Manp- $(1 \rightarrow$ & $12 \cdot 2$ & $13 \cdot 7$ & $14 \cdot 3$ & $23 \cdot 0$ & $29 \cdot 7$ \\
\hline
\end{tabular}

$\beta$ - and $(1 \rightarrow 6)-\beta$ - linkages appeared in a $3: 1$ proportion. F1S-B of Ta. leycettanus and Ta. byssochlamydoides had outer chains of $\beta$-Galf O-5-substituted, giving signals comparable to those found for the $(1 \rightarrow 5)-\beta$ galactan isolated from E. crustaceum (Leal et al., 1993).

Methylation and reductive cleavage analyses (Table 1) of the polysaccharides gave terminal Galf, O-5-substituted and O-6-substituted Galf, terminal Manp, O-2substituted, O-6-substituted and di-O-2,6-substituted Man $p$ in different proportions.

The peaks observed in the ${ }^{1} \mathrm{H}$ - and ${ }^{13} \mathrm{C}-\mathrm{NMR}$ spectra (Fig. 1) are consistent with these residues (Leal et al., 1993; Parra et al., 1994; Prieto et al., 1997). Signals corresponding to the mannan residues appeared poorly resolved in most of the cases. Hence, taking advantage of the lability of the glycosidic linkages of the furanoid rings as compared with those of the pyranoid rings, we further investigated them by selectively hydrolysing the galactofuranan moieties of all the polysaccharides to leave only the mannan skeleton.

The methylation results demonstrated that all the mannan cores also had identical residues (Table 2), although in different proportions. The ${ }^{1} \mathrm{H}-\mathrm{NMR}$ spectra of the mannans obtained are depicted in Fig. 2, the mannan from B. fulva and Th. crustaceus (not shown) being very similar to that of $P$. variotii.

By comparison with known mannan derivatives (Gorin \& Spencer, 1970; Cohen \& Ballou, 1980; Vliegenthart et al., 1983; Prieto et al., 1997) it can be deduced that all cores are constituted of $(1 \rightarrow 6)-\alpha$-mannan chains, irregularly substituted at position 2 of some of the residues either by terminal $\alpha$-mannopyranose units or else by small chains containing $\operatorname{Man} p-(1 \rightarrow 2)-\alpha$ - and Manp$(1 \rightarrow 6)-\alpha$ - linkages. To such cores, different chains of $\beta$-galactofuranose are attached in an irregular way.

\section{Immunological studies}

The titre of the sera after the fifth injection reached $1 / 8000$ for P. variotii and P. fumosoroseus, and 1/6000 for E. crustaceum. The results of inhibition studies are shown in Fig. 3. F1S-B polysaccharides of all isolates of $P$. variotii inhibited the serum anti-F1SB of $P$. variotii CBS 990.73A (Fig. 3b) at low concentrations $(3 \cdot 2-69 \cdot 3 \mathrm{~g}$ $\mathrm{ml}^{-1}$ ), but the polysaccharide F1S-B from the remaining species of section Paecilomyces studied did not block the immunological reaction (results not shown).

Fifty percent inhibition of the binding of serum antiF1SB of E. crustaceum to its specific antigen (Fig. 3a) was achieved with $4 \cdot 8,39 \cdot 0$ and $78 \cdot 0 \mathrm{~g} \mathrm{ml}^{-1}$ of the F1S-B polysaccharides of E. crustaceum, Ta. byssochlamydoides and Th.crustaceus, respectively. Polysaccharides F1S-B from other species of section Paecilomyces also inhibited the reaction, but at higher concentrations. Finally, the serum anti-F1SB of $P$. fumosoroseus did not react with any of the polysaccharides used in this study.

The hyphae of $P$. variotii CBS 990.73 A reacted with polyclonal antibodies raised against fraction F1S-B of this micro-organism as demonstrated by immunofluorescence (Fig. 4).

\section{DISCUSSION}

The polysaccharides F1S-B of the species studied from section Paecilomyces have similar structural features. All of them have a core of $(1 \rightarrow 6)-\alpha$-mannopyranose irregularly substituted at O-2 by a single $\alpha$-mannopyranose residue or small chains of mannopyranose. The degree of branching of this core depends on the species, being higher in the two Talaromyces spp. studied here. The galactofuranose residues of these polysaccharides are located in side chains of variable length (less than eight residues), O-2-linked to the mannan core. The polysaccharides studied differed in the relative proportion of the mannose and galactofuranose residues and in the presence of small amounts $(2 \cdot 5-4 \cdot 0 \%)$ of O-6-substituted galactofuranose (Table 1). The signals in the region of 5.0-5.25 p.p.m. of the ${ }^{1} \mathrm{H}-$ NMR spectra of F1S-B from P. variotii and B. fulva are similar to that of F1S-B isolated from Penicillium expansum, which is a linear polysaccharide with a highly regular structure whose repetitive unit consists of three residues of $(1 \rightarrow 5)-\beta$ - and one of $(1 \rightarrow 6)-\beta$ galactofuranose (Parra et al., 1994). These residues from Paecilomyces and Byssochlamys are components of the side chains which differ from Penicillium expansum, as shown by the shape of signals in the spectrum, because they form shorter chains that appear irregularly linked to the mannan core. In Penicillium expansum the mannan core is so small that it was not detected by NMR, although small amounts of mannose were detected in the methylation analysis. The side chains of the polysaccharides from $\mathrm{Ta}$. leycettanus and $\mathrm{Ta}$. byssochlamydoides, which lack the O-6-galactofuranose residues, are similar to the galactofuranan described in cell walls of E. crustaceum (Leal et al., 1993) and some species of Penicillium (Leal et al., 1997). Nevertheless, when the complete polysaccharides are compared, the mannose content is much higher in F1S-B from these teleomorphic species of Paecilomyces than in other species of Talaromyces which are teleomorphs of 


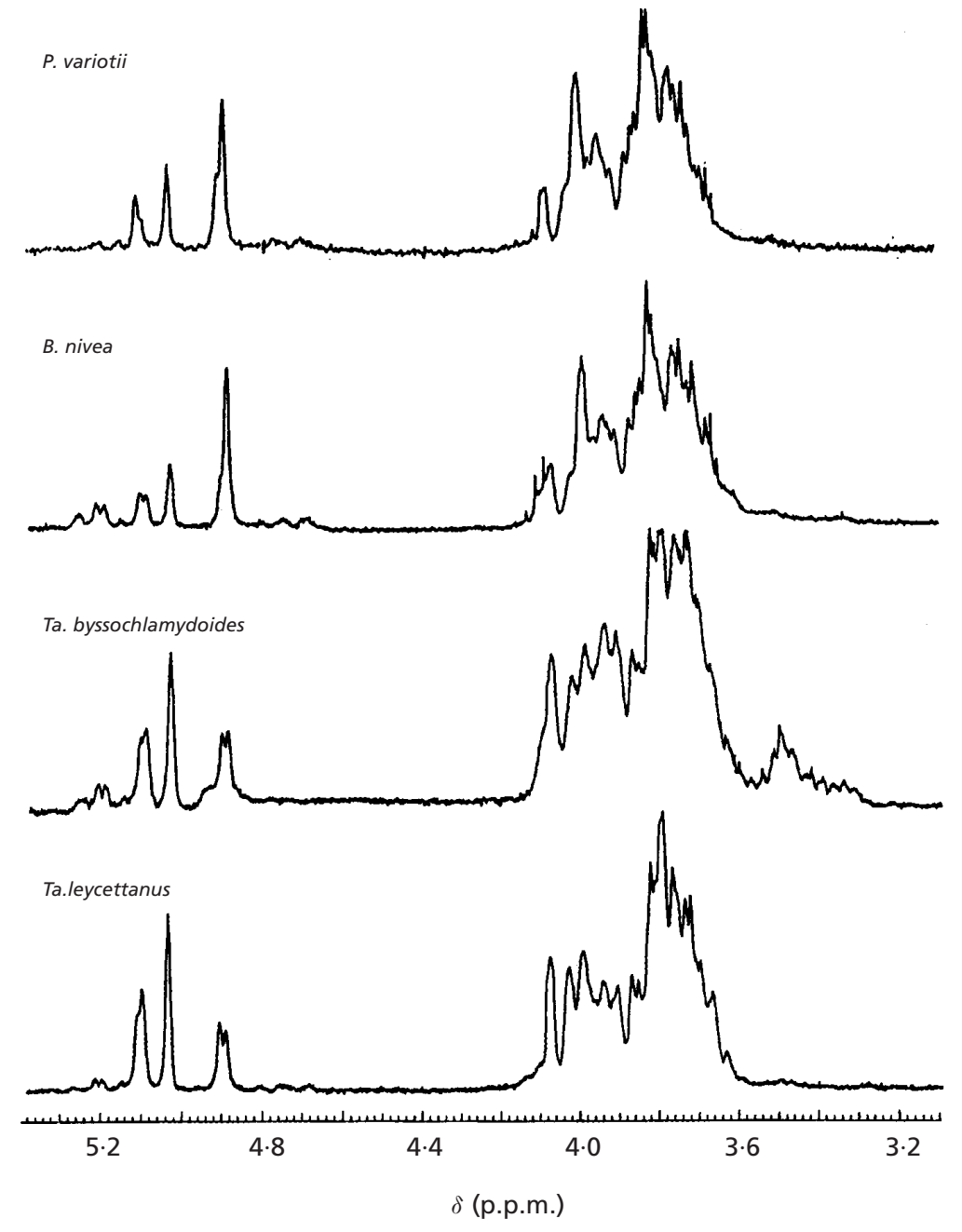

Fig. 2. ${ }^{1} \mathrm{H}-\mathrm{NMR}$ spectra of the mannan cores obtained from fraction F1S-B after partial hydrolysis. The spectrum of the mannan core from F1S-B of B. fulva (not shown) was similar to that depicted for $P$. variotii.
Penicillium. Mannans with different structures are the main components of fraction F1S of several species of Aphanoascus and of various dermatophytes (JiménezBarbero et al., 1993) included in the order Onygenales within the ascomycetous fungi. This order was rearranged by Fennell (1973), who included two families of this order in the Eurotiales, together with the family Trichocomaceae (where the genera Byssochlamys, Talaromyces and Thermoascus are included). The fruiting bodies of Eurotiales are similar to those of genera included in Onygenales, differing in the mode of conidiation (Currah, 1985). It seems that the galactomannans of the fungi of section Paecilomyces are an intermediate step in the evolution of the mannans of Onygenales towards the mannogalactans of Eurotiales, and therefore the polysaccharides may show the evolution of these micro-organisms. As Bartnicki-García (1987) stated, 'the nature of the polysaccharides in any particular fungus is not capricious, but is related to its taxonomic position and thus reflects its evolutionary history'.

Polyclonal antibodies raised against F1S-B polysaccharide from P. variotii CBS 990.73A were highly specific, since the binding to their specific antigen was only inhibited by different isolates of the same species (Fig. 3b). Polysaccharides with a structure similar to that of the antigen used, such as those from other species of section Paecilomyces, did not inhibit the immunochemical reaction. This could be related to the differences in the length of the side chains and the irregularity of the polysaccharides F1S-B of this group. Inhibition experiments were also performed using serum anti-F1S-B from E. crustaceum, which is a linear $(1 \rightarrow 5)$ $\beta$-galactofuranan (Leal et al., 1993), in order to check if these antibodies recognized the galactofuranan side chains of the polysaccharides studied here. In this case, the polysaccharides F1S-B from Ta. byssochlamydoides, $P$. variotii, Th. crustaceus and B. fulva inhibited the binding of the antiserum to its specific antigen at concentrations that varied from 9 to $300 \mu \mathrm{g} \mathrm{ml}^{-1}$. F1S-B fractions from these species have a higher content of galactofuranose than those from Ta. leycettanus and B. nivea, which reacted only at concentrations higher than $300 \mu \mathrm{g} \mathrm{ml}{ }^{-1}$. This may indicate that the $(1 \rightarrow 5)-\beta$ galactofuranose residues are immunodominant as in the extracellular polysaccharides of Penicillium and Aspergillus (Notermans et al., 1988). On the other hand, 


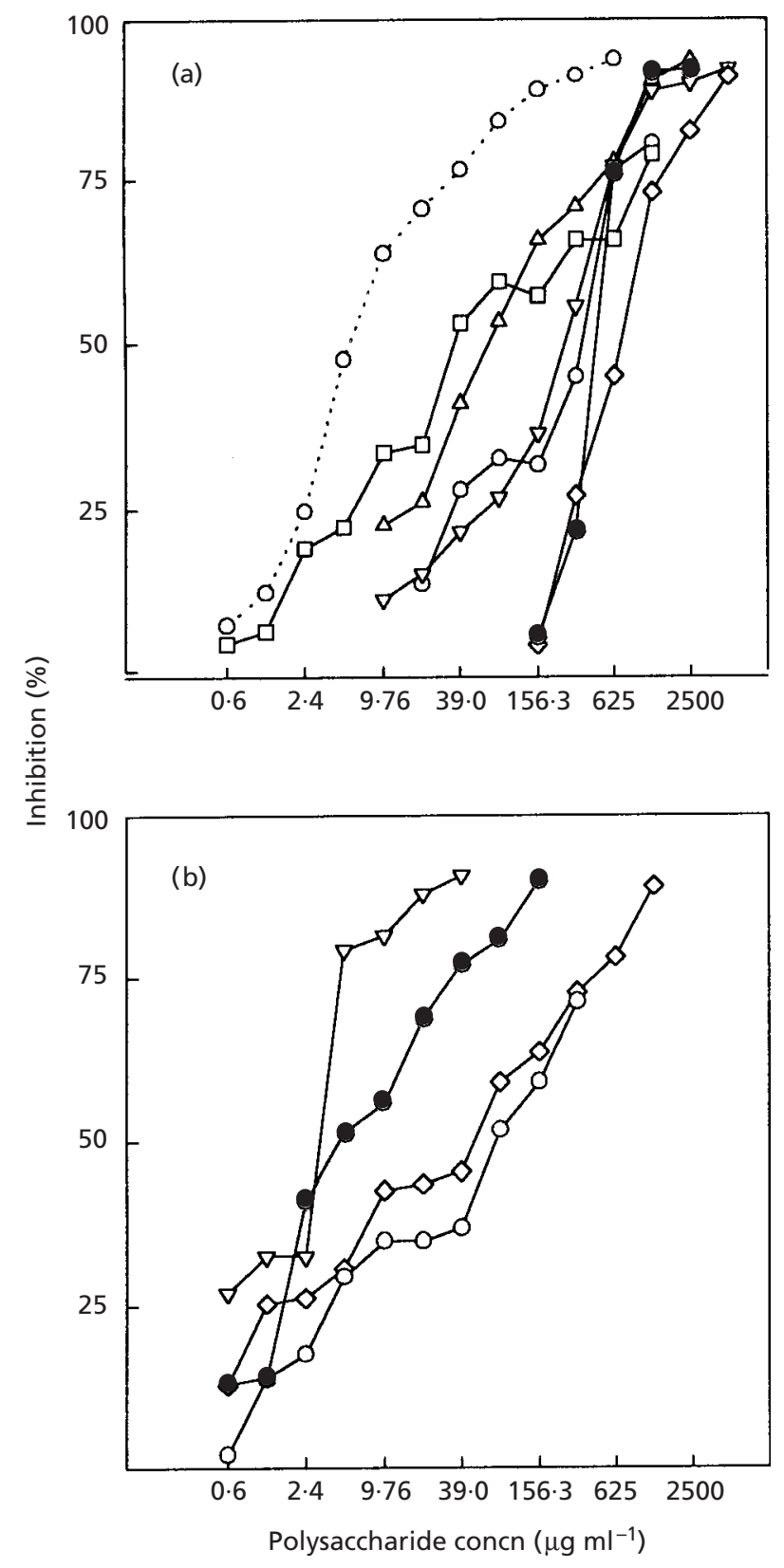

Fig. 3. Inhibition experiments. (a) Inhibition of the binding of serum anti-F1SB of $E$. crustaceum to its specific polysaccharide by several F1S-B polysaccharides. ---,--- E. crustaceum; - - , B. fulva; - -, B. nivea; $-\square-$, Ta. byssochlamydoides; $-\triangle-$, Th. crustaceus; $-\nabla-$, P. variotii; $-\triangleleft-$, Ta. leycettanus. (b) Inhibition of the binding of serum anti-F1SB of $P$. variotii CBS 990.73A to its specific polysaccharide by F1S-B polysaccharides from other isolates of the same species. - - $P$. variotii CBS $323.34 ;-\bigcirc-, P$. variotii CBS $371.70 ;-\diamond-, P$. variotii CBS $339.51 ;-\nabla-, P$. variotii CBS 990.73A. All values are means of triplicate determinations.

the polysaccharides of fungi from section Paecilomyces did not inhibit the binding of the serum anti-F1SB of $P$. fumosoroseus to its specific antigen, a $(1 \rightarrow 6)-\alpha$-mannan substituted at $\mathrm{O}-4$ by one residue of $\beta$-galactopyranose or $\alpha$-glucopyranose.

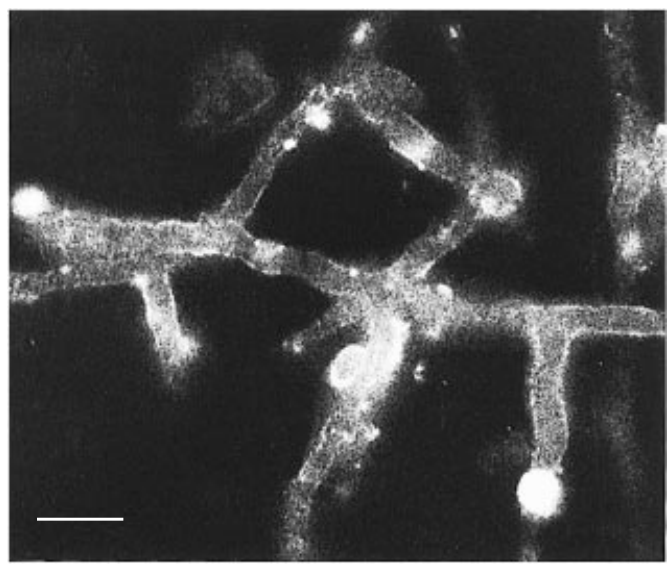

Fig. 4. Immunofluorescence studies. Hyphae of $P$. variotii $C B S$ 990.73A were grown on coverslips, heat-fixed and stained by reaction with serum anti-F1S-B followed by goat antirabbit IgG-rhodamine conjugate. No immunofluorescence was observed when mycelium was treated with preimmune serum (not shown). Bar, $10 \mu \mathrm{m}$.

Mycelium of $P$. variotii reacted specifically with serum anti-F1S-B of the same species (Fig. 4), indicating the accessibility of the epitope in the hyphae. This would allow the detection of fungal contamination in food and biological samples.

The structure of the polysaccharides F1S-B from fungi of section Paecilomyces presented in this work differs from the one described for $P$. fumosoroseus and P. farinosus from section Isarioidea (Domenech et al., 1996) indicating the heterophyletic character of the genus Paecilomyces. The availaible data support the division of the genus into two sections. The characteristic polysaccharides from both sections are different from those described for Penicillium species. The existing classification of the genus was proposed by Samson (1974) on the basis of the morphology and the structure of the phialides and conidiophores. More recent studies using molecular techniques, such as the cladistic analysis of PCR-based DNA markers, clearly showed that morphological characteristics of asexual structures are insufficient to yield a cohesive taxonomy of Paecilomyces, and that classifications based on morphological criteria alone had problems in distinguishing among species of closely related genera (Tigano-Milani et al., 1995). It is interesting to note that F1S-B polysaccharides from the two species of Talaromyces included in this work (Ta. leycettanus and Ta. byssochlamydoides) are clearly distinct from the complex glucogalactans with small amounts of mannose found in species of the same genus which are closely related to Penicillium (Prieto et al., 1995). Our data reinforce the results of rDNA analysis (Taylor et al., 1990) showing that Ta. leycettanus and $\mathrm{Ta}$. byssochlamydoides are closely related to Byssochlamys and Thermoascus and phylogenetically separated from other Talaromyces, and agree with the proposal of Pitt (1993) that Talaromyces species 
with Paecilomyces anamorphs should be transferred to Byssochlamys.

As has been shown in other fungal taxa, polysaccharides seem to be useful characters for delimiting genera and establishing relationships among anamorphs and teleomorphs (Leal et al., 1992, 1997; Domenech et al., 1994, 1996; Leal, 1994; Jiménez-Barbero et al., 1995 ; Prieto et al., 1995, 1997; Leal \& Bernabé, 1998).

\section{ACKNOWLEDGEMENTS}

We thank Mr. J. López for technical assistance. This work was supported by Grants PB 95/0078 and 93/1027 from Dirección General de Investigación Científica y Técnica.

\section{REFERENCES}

Adams, G. A. (1965). Complete acid hydrolysis. Methods Carbobydr Chem 5, 269-276.

Aoki, J. \& Yanase, K. (1970). Phenol oxidase activity in the integument of the silk-worm Bombyx mori infected with Beauvearia bassiana and Spicaria fumoso-rosea. J Invertebr Pathol 16, 459-464.

Bartnicki-García, S. (1970). Cell wall composition and other biochemical markers in fungal phylogeny. In Phytochemical Phylogeny, pp. 81-103. Edited by J. B. Harborne. New York \& London: Academic Press.

Bartnicki-García, S. (1987). The cell wall: a crucial structure in fungal evolution. In Evolutionary Biology of the Fungi, pp. 389-403. Edited by A. D. M. Rayner, C. M. Brasier \& D. Moore. Cambridge: Cambridge University Press.

Berbee, M. L., Yoshimura, A., Sugiyama, J. \& Taylor, J. W. (1995). Is Penicillium monophyletic? An evaluation of phylogeny in the family Trichocomaceae from $18 \mathrm{~S}, 5 \cdot 8 \mathrm{~S}$ and ITS ribosomal DNA sequence data. Mycologia 87, 210-222.

Brown, A. H. \& Smith, G. (1957). The genus Paecilomyces Bainier and its perfect stage Byssochlamys Westling. Trans Br Mycol Soc 40, 17-89.

Byrd, R. P., Jr, Roy, T. M., Fields, C. L. \& Lynch, J. A. (1992). Paecilomyces variotii pneumonia in a patient with diabetes mellitus. J Diabetes Complicat 6, 150-153.

Cohen, R. E. \& Ballou, C. E. (1980). Linkage analysis of mannoserich glycoprotein core oligosaccharides by proton nuclear magnetic resonance spectroscopy. Biochemistry 19, 4345-4358.

Currah, R. S. (1985). Taxonomy of the Onygenales: Athrodermataceae, Gymnoascaceae, Myxotrichaceae and Onygenaceae. Mycotaxon 24, 1-216.

De Ruiter, G. A., Van Bruggen-van der Lugt, A. W., Nout, M. J. R., Middlehoven, W. J., Soentoro, P. S. S., Notermans, S. H. W. \& Rombouts, F. M. (1992). Formation of antigenic extracellular polysaccharides by selected strains of Mucor spp., Rhizopus spp., Rhizomucor spp., Absidia corymbifera and Syncephalastrum racemosum. Antonie Leeuwenhoek 62, 189-199.

Domenech, J., Prieto, A., Bernabé, M. \& Leal, J. A. (1994). Cell wall polysaccharides of four strains of P. variotii. Curr Microbiol 28, 169-173.

Domenech, J., Barasoaín, I., Prieto, A., Gómez-Miranda, B., Bernabé, M. \& Leal, J. A. (1996). An antigenic water-soluble glucogalactomannan extracted from cell walls of Paecilomyces fumosoroseus and Paecilomyces farinosus. Microbiology 42, 3497-3503.

Dubois, M., Gilles, K. A., Rebers, P. A. \& Smith, F. A. (1956).
Colorimetric method for determination of sugars and related substances. Anal Chem 28, 350-356.

Engel, G. \& Teuber, M. (1991). Heat resistance of ascospores of Byssochlamys nivea in milk and cream. Int J Food Microbiol 12, 225-233.

Fennell, D. I. (1973). Plectomycetes: Eurotiales. In The Fungi, vol. IVA, pp. 45-68. Edited by C. Ainsworth \& A. S. Sussman. New York \& London: Academic Press.

Gailliez, J. C. \& Poulain, D. (1988). Analyse cytologique de l'expression d'un épitope porté par les glycoprotéins excretées par Candida albicans. Ann Inst Pasteur Microbiol 139, 171-188.

Gerwig, G. J., Kamerling, J. P. \& Vliegenthart, J. F. (1978). Determination of the $\mathrm{D}$ and $\mathrm{L}$ configuration of neutral monosaccharides by high-resolution capillary G. L. C. Carbohydr Res 62, 349-357.

Gómez-Miranda, B., Rupérez, P. \& Leal, J. A. (1981). Changes in chemical composition during germination of Botrytis cinerea sclerotia. Curr Microbiol 6, 243-246.

Gómez-Miranda, B., Prieto, A. \& Leal, J. A. (1990). Chemical composition and characterization of a galactomannoglucan from Gliocladium viride wall material. FEMS Microbiol Lett 70, 331-336.

Gorin, P. A. \& Spencer, J. F. T. (1970). Proton magnetic resonance spectroscopy - an aid in identification and chemotaxonomy of yeasts. Adv Appl Microbiol 13, 25-89.

Gray, G. R. (1987). Reductive cleavage of permethylated polysaccharides. Methods Enzymol 138, 26-38.

Hearn, V. M. (1991). Glycoproteins of Aspergillus fumigatus cell wall. In Fungal Cell Wall and Immune Response, NATO ASI Series H, Cell Biology, vol. 53, pp. 219-228. Edited by J. P. Latgé $\&$ D. Boucias. Berlin: Springer.

Jiménez-Barbero, J., Bernabé, M., Leal, J. A., Prieto, A. \& GómezMiranda, B. (1993). Chemical structure and conformational features of cell-wall polysaccharides isolated from Aphanoascus mephitalus and related species. Carbohydr Res 250, 289-299.

Jiménez-Barbero, J., Prieto, A., Gómez-Miranda, B., Leal, J. A. \& Bernabé, M. (1995). Chemical structure of fungal cell-wall polysaccharides isolated from Microsporum gypseum and related species of Microsporum and Trychophyton. Carbohydr Res 272, 121-128.

Kamphuis, H. J., De Ruiter, G. A., Veeneman, G. H., Van Boom, J. H., Rombouts, F. M. \& Notermans, S. H. W. (1992). Detection of Aspergillus and Penicillium extracellular polysaccharides (EPS) by ELISA: using antibodies raised against acid hydrolysed EPS. Antonie Leeuwenhoek 61, 323-332.

King, D. A., Jr, Michener, H. D. \& Ito, K. A. (1969). Control of Byssochlamys and related heat-resistant fungi in grape products. Appl Microbiol 18, 166-173.

Leal, J. A. (1994). Water-soluble polysaccharides of fungal cell walls. In Microorganisms in Ruminant Nutrition, pp. 153-165. Edited by R. A. Prins \& C. S. Stewart. Nottingham: Nottingham University Press.

Leal, J. A. \& Bernabé, M. (1998). Taxonomic applications of polysaccharides. In Chemical Fungal Taxonomy, pp. 153-181. Edited by J. C. Frisvad, P. D. Bridge \& D. K. Arora. New York \& Hong Kong: Marcel Dekker.

Leal, J. A., Gómez-Miranda, B., Bernabé, M., Cano, J. \& Guarro, J. (1992). The chemical composition of six species of Aphanoascus: the taxonomic significance of the presence of $\alpha-(1-2)-(1-6)$ mannan and $\alpha-(1-4)$ glucan. Mycol Res 96, 363-368.

Leal, J. A., Prieto, A., Gómez-Miranda, B., Jiménez-Barbero, J. \& Bernabé, M. (1993). Structure and conformational features of an 
alkali- and water-soluble galactofuranan from the cell walls of Eupenicillium crustaceum. Carbohydr Res 244, 361-368.

Leal, J. A., Gómez-Miranda, B., Prieto, A., Domenech, J., Ahrazem, O. \& Bernabé, M. (1997). Possible chemotypes from cell wall polysaccharides as an aid in the systematics of the genus Penicillium and its teleomorphic states Eupenicillium and Talaromyces. Mycol Res 101, 1259-1264.

Notermans, S. \& Soentoro, P. S. S. (1986). Immunological extracellular polysaccharide antigens produced by different mould species. Antonie Leeuwenhoek 52, 393-401.

Notermans, S., Wieten, G., Engel, H. W. B., Rombouts, F. M., Hoogerhout, P. \& Van Boom, J. H. (1987). Purification of extracellular polysaccharides (EPS) antigens produced by different mould species. J Appl Bacteriol 62, 157-166.

Notermans, S., Dufrenne, J., Wijnands, L. M. \& Engel, H. W. B. (1988). Human serum antibodies to extracellular polysaccharides (EPS) of moulds. Int J Food Microbiol 2, 247-258.

Parra, E., Jiménez-Barbero, J., Bernabé, M., Leal, J. A., Prieto, A. \& Gómez-Miranda, B. (1994). Structural investigation of two cell wall polysaccharides of Penicillium expansum strains. Carbohydr Res 257, 239-248.

Pitt, J. I. (1993). Speciation and evolution in Penicillium and related genera. In The Fungal Holomorph: Mitotic, Meiotic and Pleomorphic Speciation in Fungal Systematics, pp. 107-113. Edited by D. R. Reynolds \& J. W. Taylor. Wallingford: CAB International.

Prieto, A., Bernabé, M. \& Leal, J. A. (1995). Isolation, purification and chemical characterization of alkali-extractable polysaccharides from the cell walls of Talaromyces species. Mycol Res 99, 69-75.

Prieto, A., Leal, J. A., Poveda, A., Jiménez-Barbero, J., GómezMiranda, B., Domenech, J., Ahrazem, O. \& Bernabé, M. (1997). Structure of complex cell wall polysaccharides isolated from Trichoderma and Hypocrea species. Carbohydr Res 304, 281-291.
Rath, J., Messner, R., Kosma, P., Altmann, F., März, L. \& Kubicek, C. P. (1995). The $\alpha$-D-mannan core of a complex cell-wall heteroglycan of Trichoderma reesei is responsible for $\beta$-glucosidase activation. Arch Microbiol 164, 414-419.

Samson, R. A. (1974). Paecilomyces and some allied hyphomycetes. Stud Mycol 6, 1-119.

Sridhara, S., Gandal, S. V. \& Joshi, A. P. (1990). Immunochemical investigation of allergens from Rhizopus nigricans. Allergy 45, 577-586.

Taylor, J. W., Pitt, J. I. \& Hocking, A. D. (1990). Ribosomal DNA restriction studies of Talaromyces species with Paecilomyces and Penicillium anamorphs. In Modern Concepts in Penicillium and Aspergillus Classification, pp. 357-370. Edited by R. A. Samson $\&$ J. I. Pitt. New York: Plenum.

Tigano-Milani, M. S., Samson, R. A., Martins, I. \& Sobral, B. W. S. (1995). DNA markers for differentiating isolates of Paecilomyces lilacinus. Microbiology 141, 239-245.

Vliegenthart, J. F. G., Dorland, L. \& van Halbeck, H. (1983). Highresolution ${ }^{1} \mathrm{H}-\mathrm{NMR}$ spectroscopy as a tool in the structural analysis of carbohydrates related to glycoproteins. Adv Carbobydr Chem Biochem 41, 209-374.

Weijman, A. C. M. \& Golubev, W. I. (1987). Carbohydrate patterns and taxonomy of yeasts and yeast-like fungi. In The Expanding Realm of Yeast-like Fungi, pp. 361-371. Edited by G. S. de Hoog, M. T. H. Smith \& A. C. M. Weijman. Amsterdam: Elsevier.

Weijman, A. C. M. \& Van der Walt, J. P. (1989). Carbohydrate profiles and the taxonomic concept in the Lipomycetaceae. Stud Mycol 31, 193-199.

Weijman, A. C. M., Vlug, I. J. A. \& Van Eijk, G. W. (1982). Carbohydrate patterns. Stud Mycol 22, 50-53.

Received 8 February 1999; revised 10 June 1999; accepted 18 June 1999. 